\title{
Mortality in heart failure: clinical variables of prognostic value
}

\author{
JOHN G F CLELAND, * HENRY J DARGIE, * IAN FORD $\dagger$ \\ From the ${ }^{\star}$ Department of Cardiology, Western Infirmary, Glasgow, and †Department of Statistics, University \\ of Glasgow
}

SUMMARY One hundred and fifty two patients with chronic heart failure caused primarily by left ventricular dysfunction were followed prospectively in an open study for a mean period of 21 months. The effects of several clinical variables on subsequent outcome were examined, including the effects of treatment, which was determined by the clinician caring for the patient and was not randomly allocated. In order of importance, frequent ventricular extrasystoles, non-treatment with amiodarone, low mean arterial pressure, and a diagnosis of coronary artery disease were associated with a poor prognosis, with each of these variables providing extra predictive information independently of the others. Initial serum potassium concentration and treadmill exercise time also carried further weak but independent prognostic information. Neither treatment with angiotensin converting enzyme inhibitors nor digoxin appeared to affect outcome. Left ventricular function (as reflected by $M$ mode echocardiography) and the dose of diuretic also failed to predict outcome. There did, however, appear to be a reduction in the frequency of sudden death when angiotension converting enzyme inhibitors were given.

Further studies are required to confirm the adverse prognostic significance of ventricular arrhythmias in patients with heart failure and the possible benefit associated with amiodarone treatment.

Chronic heart failure is a condition of varied aetiology that imposes a heavy burden of symptoms, confers a very poor prognosis, ${ }^{1-3}$ and affects $4 \%$ of the population under the age of 75 years. ${ }^{4}$ Once an in-hospital diagnosis of heart failure has been made, the annual mortality is likely to be $40 \%$ or more, ${ }^{1-3}$ though the prognosis seems to be slightly better in those patients not referred to hospital and who, presumably, have milder disease.

The most frequently reported mode of death in patients with heart failure seems to be sudden, ${ }^{2} 35$ presumably caused by ventricular arrhythmias, ${ }^{6}$ which are common. ${ }^{178}$ Many $^{1910}$ but not all ${ }^{11-13}$ workers suggest that these arrhythmias are powerful independent prognostic indicators for mortality. Whether they are of primary importance or merely reflect the extent of left ventricular dysfunction is

Requests for reprints to Dr John G F Cleland, Waller Department of Cardiology, St Mary's Hospital, Praed Street, Paddington, London W2 1 NY.

Accepted for publication 21 July 1987 unclear at present. ${ }^{11013}$ One retrospective casecontrol study suggested no reduction in mortality with procainamide, ${ }^{14}$ though anecdotal comment has suggested a possible benefit with amiodarone. ${ }^{15}$ Another prospective study suggested that arrhythmias in patients with heart failure are resistant to treatment. " "Vasodilator" treatment on the other hand has been shown to improve outcome. ${ }^{1718}$

We investigated the importance of arrhythmias, left ventricular function, treatment, functional capacity, and biochemical indices in predicting outcome in a large series of patients with heart failure followed prospectively in an open study.

\section{Patients and methods}

\section{PATIENTS}

One hundred and fifty two patients in whom a diagnosis of heart failure was established on clinical, radiological, and echocardiographic grounds were recruited. All were symptomatically stable but in New York Heart Association classes II-IV (mean (1 SD) $2 \cdot 8(0 \cdot 8)$ ). The mean (1 SD) age was $59(9)$ 
years, $84 \%$ were male, and the mean (SD) duration of heart failure was 18(19) months (all $>3$ months).

One hundred and four had received digoxin for more than one month before entry to the study and all were receiving frusemide in a mean (1 SD) daily dose of $127(85) \mathrm{mg} /$ day. No patients were on potassium-sparing diuretics but 47 were on potassium chloride supplements (median dose 1800 $\mathrm{mg} /$ day).

The diagnosis was ischaemic heart disease in 93, idiopathic congestive (dilated) cardiomyopathy in 28 , residual left ventricular dysfunction after successful valve replacement in 16 , secondary to hypertension in nine, and alcohol related cardiomyopathy in six. Patients in whom angina was an appreciable complaint at rest or during exercise were excluded. The absence of coronary artery disease was always confirmed by coronary angiography; coronary artery disease was diagnosed either at coronary angiography or after myocardial infarction with typical history and electrocardiographic and enzyme changes.

Patients were allocated to angiotensin converting enzyme inhibitors or amiodarone on an open basis, either in the context of a clinical trial ${ }^{19}$ or for clinical reasons on the order of the attending physician. Selection of patients was not systematic and criteria varied over the period of observation. Patients were therefore not necessarily selected for angiotensin converting enzyme inhibitors or treatment with amiodarone on the basis of severity of heart failure or the presence of arrhythmias. This reflects the uncertainty of the clinical value of these drugs during much of the observation period. Amiodarone was started at $200 \mathrm{mg}$ three times a day in most cases, with a mean (1 SD) daily maintenance dose of 183 (54) $\mathrm{mg} /$ day (range $100-400 \mathrm{mg} /$ day).

\section{METHODS}

New York Heart Association scores were determined in the light of the exercise performance. Heart rate was measured from the apex beat and blood pressure was recorded with a Hawkesley random zero sphygmomanometer.

A 12 lead electrocardiogram was recorded before a graded treadmill test by a modified Bruce protocol. Forty eight hour ambulatory monitoring was also performed with a Medilog I system and the results were analysed with a Pathfinder Analyser under constant visual monitoring. Ventricular tachycardia was defined as $\geqslant 3$ consecutive ventricular extrasystoles at $>120$ beats/minute.

$M$ mode echocardiography was performed with the patients in the left lateral position.

Blood was taken for measurement of serum sodium, potassium, and creatinine concentrations on at least two and up to five occasions at different times of day and an average value was taken. The median number of samples taken was three. Blood was taken for measurement of serum digoxin concentration at least six hours after the last dose.

\section{DEFINITION OF MODES OF DEATH}

The mode of death was ascertained either from the deceased's relatives, from the family practitioner, or from the observations of the hospital staff. Where death was believed to be from cardiac causes, it was classified as death from pulmonary oedema, cardiogenic shock, or sudden (defined as death without reporting a change in symptoms in the 24 hours before death to lay or medical persons). Sudden death was also divided into cases that had or had not indicated some gradual chronic deterioration of symptoms of heart failure in the months before death.

\section{STATISTICAL ANALYSIS}

Means (1 SD) are given for the study group and treatment subgroups. Means of subgroups were compared by two-sample $t$ tests. The log-rank test ${ }^{20}$ was used to compare survival rates in the treatment subgroups. Cox's proportional hazards model ${ }^{21}$ was used to correct for and identify important covariates. A stepwise routine ${ }^{22}$ was used to identify the best subset of predictors. Both forward and backward stepping was used to protect against the omission of important predictors. Pearson's product moment correlation coefficients were calculated to investigate interrelations between the prognostic indicators and the other variables. Estimated survival curves were subsequently constructed for each treatment and for each of the variables independently related to outcome. This was done by fixing at median values all variables that carried independent predictive information other than the one tested.

\section{Results}

\section{CLINICAL OUTCOME}

The mean follow up time was 21 (12) months, during which 63 patients $(41 \%)$ died. Forty seven $(75 \%)$ of the deaths were sudden, though in 12 $(26 \%)$ patients clinical deterioration was noted at the follow up clinic in the months before death. Five patients died in cardiogenic shock after recurrent myocardial infarction and two died after cerebrovascular accidents. One patient died after mesenteric artery occlusion, one soon after peripheral vascular surgery, one from chronic lymphatic leukaemia and associated respiratory infection, and one from rectal carcinoma. Only five $(8 \%)$ deaths were considered to be caused by intractable left ven- 
tricular failure. Four patients presented with sustained ventricular tachycardia during follow up. None was on antiarrhythmic treatment at the time. Although treatment with procainamide in two cases, tocainide in one case, and amiodarone in one case was started, all four subsequently died.

\section{PREVALENCE OF ARRHYTHMIAS}

The mean frequency of ventricular extrasystoles over 24 hours was 4321 (median value 1375, range 0-24299). Seventy nine per cent of patients had couplets or salvoes of ventricular extrasystoles on ambulatory monitoring (mean 15 , median 5 , range 0-768 per 24 hours). Sixty one per cent of patients had one or more episodes of ventricular tachycardia with a mean overall frequency of seven (median value 2 , range $0-201$ ) in 24 hours.

\section{BASELINE CHARACTERISTICS}

The mean initial heart rate was 88 (14) beats/min and mean arterial pressure was 91 (14) $\mathrm{mm} \mathrm{Hg}$. Forty five patients $(30 \%)$ had left bundle branch block. The mean concentration of serum sodium was $136+10 \mathrm{mmol} / 1$, of serum potassium $3.8(0.4)$ $\mathrm{mmol} / \mathrm{l}$, and of serum creatinine $117(27) \mu \mathrm{mol} / 1$. The mean end diastolic left ventricular dimension was $6.7(0.8) \mathrm{cm}$ and end systolic dimension was 5.7 $(0.9) \mathrm{cm}$. The resulting fractional shortening was $15 \cdot 3(6 \cdot 5) \%$.

\section{CHANGES IN TREATMENT}

During follow up 11 patients were started on nitrate treatment, one on prazosin, and three on hydralazine. In 18 patients an increase in diuretic treatment was required, and in six patients who were taking angiotensin converting enzyme inhibitors the dose of diuretic was reduced because of postural hypotension. As mentioned above four patients were treated with antiarrhythmic agents for sustained ventricular tachycardia at a time other than entry to the study. Nineteen patients were taking potassiumsparing diuretics: amiloride in $14(10-20 \mathrm{mg} /$ day $)$ and spironolactone in five $(25-50 \mathrm{mg} /$ day). Only three of these were in the group treated with angiotensin converting enzyme inhibitors.

\section{COMPARISON OF TREATMENT SUBGROUPS}

Those treated with amiodarone were well matched in all respects with those who did not receive this treatment (table 1). Those subjects treated with angiotensin converting enzyme inhibitors (table 2) had significantly worse New York Heart Association scores, tended to have shorter exercise times, more episodes of ventricular tachycardia, and required significantly more frusemide and digoxin.

Patients taking digoxin (table 3 ) had worse New
Table 1 Comparison between patients taking amiodarone and those not taking amiodarone

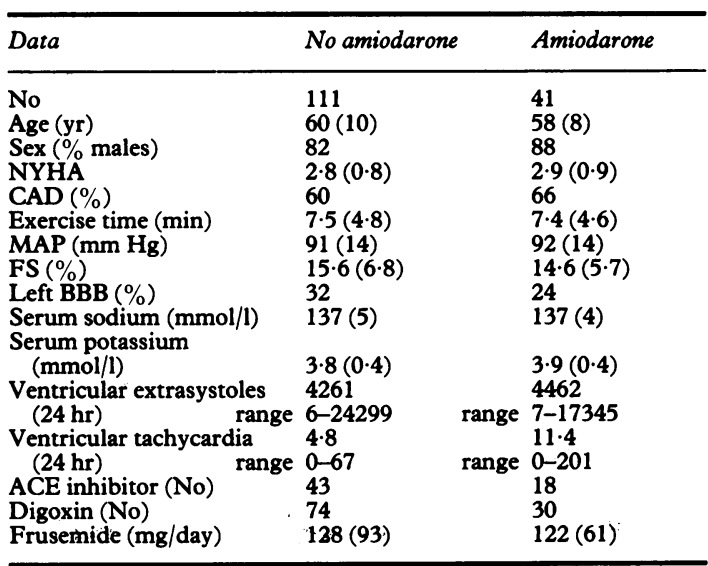

Values are mean (1 SD), or range. ACE, angiotensin converting enzyme; NYHA, New York Heart Association functional class; CAD, coronary artery disease; MAP, mean arterial pressure; FS, echocardiographic left ventricular fractional shortening; BBB, bundle branch block.

York Heart Association scores than those not on digoxin.

\section{PREDICTORS OF PROGNOSIS}

Several variables were found to be of prognostic value by Cox's proportional hazards model (table 4). Stepwise regression with Cox's proportional hazards model showed that in order of importance ventricular extrasystoles $(p<0.0001)$, amiodarone treatment $(p<0.001)$, mean blood pressure $(p<$

Table 2 Comparison between patients taking an $A C E$ inhibitor and those not taking an ACE inhibitor

\begin{tabular}{|c|c|c|}
\hline Data & $\begin{array}{l}\text { No } A C E \\
\text { inhibitor }\end{array}$ & $\begin{array}{l}A C E \\
\text { inhibitor }\end{array}$ \\
\hline 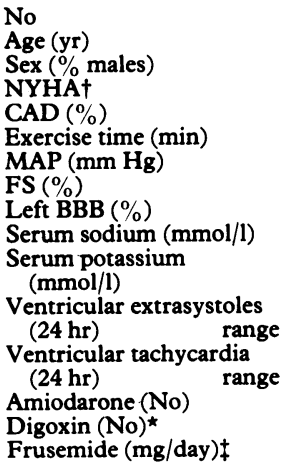 & $\begin{array}{l}91 \\
59(10) \\
89 \\
2 \cdot 6(0 \cdot 7) \\
65 \\
8 \cdot 0(4 \cdot 5) \\
93(15) \\
16 \cdot 1(6 \cdot 3) \\
32 \\
137(8)\end{array}$ & $\begin{aligned} & 61 \\
& 59(8) 75 \\
& 3 \cdot 1(0 \cdot 8) 56 \\
& 6 \cdot 6(5 \cdot 0) \\
& 88(13) \\
& 14 \cdot 3(6 \cdot 7) \\
& 27 \\
& 136(6) \\
& \\
& 3 \cdot 7(0 \cdot 4) \\
& 4592 \\
& \text { range } 0-24299 \\
& 10 \\
& \text { range } 0-201 \\
& 18 \\
& 55 \\
& 163(106)\end{aligned}$ \\
\hline
\end{tabular}

See footnote to table 1 for abbreviations.

${ }^{\star} \mathrm{p}<0.05 .+\mathrm{p}<0.01$. $\mathrm{p} p<0.001$. 
Table 3 Comparison between patients taking digoxin and those not taking digoxin

\begin{tabular}{|c|c|c|}
\hline Data & No digoxin & Digoxin \\
\hline $\begin{array}{l}\text { No } \\
\text { Age (yr) } \\
\text { Sex (\% males) } \\
\text { NYHA } \\
\text { CAD (\%) } \\
\text { Exercise time (min) } \\
\text { MAP (mm Hg) } \\
\text { FS (\%) } \\
\text { Left BBB (\%) } \\
\text { Serum sodium (mmol/l) } \\
\text { Serum potassium } \\
\quad \text { (mmol/l) } \\
\text { Ventricular extrasystoles } \\
\quad(24 \text { hr) } \\
\text { Ventricular tachycardia } \\
\quad(24 \text { hr) range } \\
\text { Amiodarone (No) range } \\
\text { ACE inhibitor (No) }+ \\
\text { Frusemide (mg/day) }\end{array}$ & $\begin{array}{l}48 \\
59(11) \\
89 \\
2 \cdot 5(0 \cdot 7) \\
50 \\
8 \cdot 0(4 \cdot 5) \\
93(13) \\
16 \cdot 6(6 \cdot 3) \\
37 \\
138(5)\end{array}$ & $\begin{aligned} & 3.8(0.4) \\
& 4692 \\
& \text { range } 7-24299 \\
& 7 \cdot 6 \\
& \text { range } 0-201 \\
& 30 \\
& 55 \\
& 143(92)\end{aligned}$ \\
\hline
\end{tabular}

See footnote to table 1 for abbreviations.

${ }^{\star} \mathrm{p}<0.03$. tp $<0.01$.

0.001 ), and a diagnosis of coronary artery disease $(p<0.001)$ were of important independent prognostic value. Initial serum potassium concentration $(p<0.02)$ and exercise time $(p<0.03)$ were found to be of some additional independent predictive value.

\section{EFFECTS OF TREATMENT}

Amiodarone treatment seemed to improve the prognosis ( $p<0.01$ ) (fig 1 ); this reduction in mortality was largely caused by a decline in the oecurrence of sudden death, as $45 \%$ of those not treated with amiodarone died suddenly compared with $15 \%$ of

Table 4 Prognostic value of variables analysed by Cox's proportional hazards model (univariate analysis)

\begin{tabular}{ll}
\hline & Statistical \\
Variable & significance \\
\hline Ventricular extrasystoles $(24 \mathrm{~h})$ & $\mathrm{p}<0.0001$ \\
Mean arterial pressure $(\mathrm{mm} \mathrm{Hg})$ & $\mathrm{p}<0.0001$ \\
Serum potassium (mmol/l) & $\mathrm{p}<0.0001$ \\
Serum sodium (mmol/l) & $\mathrm{p}<0.0001$ \\
Exercise time (min) & $\mathrm{p}<0.0001$ \\
NYHA score & $\mathrm{p}<0.0001$ \\
Amiodarone treatment & $\mathrm{p}<0.01$ \\
Echocardiographic end systolic dimension & $\mathrm{p}<0.01$ \\
$\quad$ (cm) & $\mathrm{p}<0.01$ \\
Echocardiographic fractional shortening (\%) & $\mathrm{p}<0.01$ \\
Left bundle branch block & \\
Echocardiographic end diastolic dimension & $\mathrm{p}<0.02$ \\
$\quad$ (cm) & $\mathrm{p}<0.06$ \\
Diagnosis of coronary artery disease & $\mathrm{p}<0.06$ \\
Ventricular tachycardia (/24 h) & $\mathrm{p}<0.07$ \\
Age (years) & $\mathrm{p}<0.1$ \\
Frusemide dose (mg/day) & $\mathrm{p}<0.7$ \\
Duration of symptoms & $\mathrm{p}<0.8$ \\
Heart rate (beats/min) & $\mathrm{p}=0.93$ \\
Captopril treatment & $\mathrm{p}=0.99$ \\
Digoxin treatment & \\
\hline
\end{tabular}

those treated with amiodarone during the follow up period. While angiotensin converting enzyme inhibitors had no overall beneficial effect on mortality (fig 2), the frequency of sudden death was less $(21 \%$ vs $37 \% ; p<0.05)$. There were six $(10 \%)$ deaths (see above) caused by vascular events in the group on angiotensin converting enzyme inhibitors but only three $(3 \%)$ in the group not treated with angiotensin converting enzyme inhibitors (NS). Treatment with digoxin (fig 3 ) and diuretic dose did not alter the overall prognosis or the frequency of sudden death before or after adjustment for the covariates. Separate analysis of those patients undergoing a change in treatment showed no alteration in prognosis. Potassium supplements did not affect prognosis.

\section{RELATION OF VENTRICULAR EXTRASYSTOLES TO OTHER MEASURED VARIABLES}

Ventricular extrasystoles were correlated with the frequency of more complex ventricular extrasystoles $(r=0.66 ; p<0.0001)$ and were also associated with a worse New York Heart Association score ( $p$ < 0.001 ). However, no association was noted with the use of digoxin or with concentrations of serum digoxin (0.8-2.3 nmol/1) (all of which were in the therapeutic range $<2.6 \mathrm{nmol} / \mathrm{l})$. Exercise time $(\mathrm{r}=$ $-0.45 p<0.001)$, serum potassium $(r=-0.38$

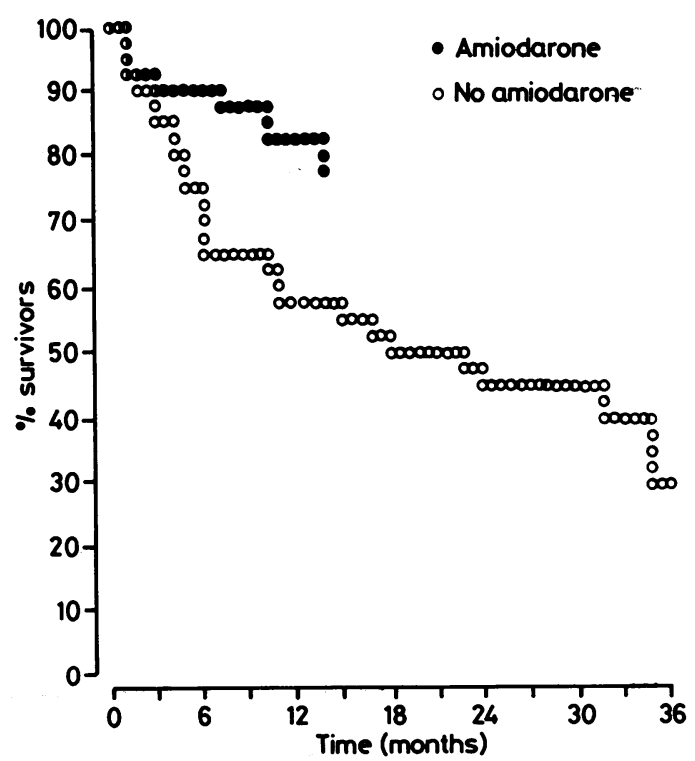

Fig 1 Cumulative proportion surviving (log rank test). Patients on amiodarone faired better $(p<0.01)$. Note that no events occurred in the amiodarone treated patients after 15 months and no valid prediction of subsequent mortality can be made from this analysis. 


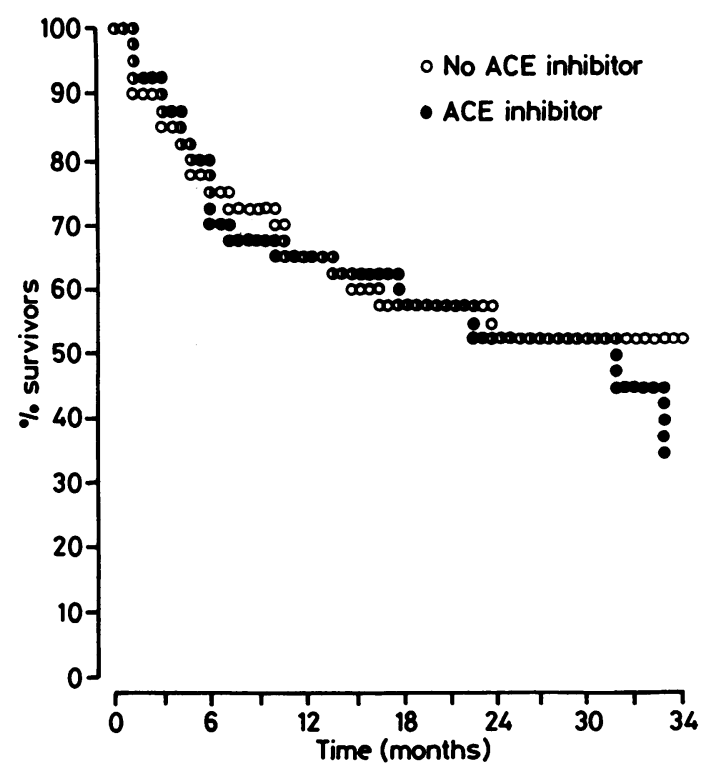

Fig 2 Log rank survival curves comparing patients treated with or without angiotensin converting enzyme inhibitors. No difference was noted.

$\mathrm{p}<0.001)$, and left bundle branch block $(\mathrm{r}=0.35$ $\mathrm{p}<0.001$ ) were the best predictors of the frequency of ventricular arrhythmias.

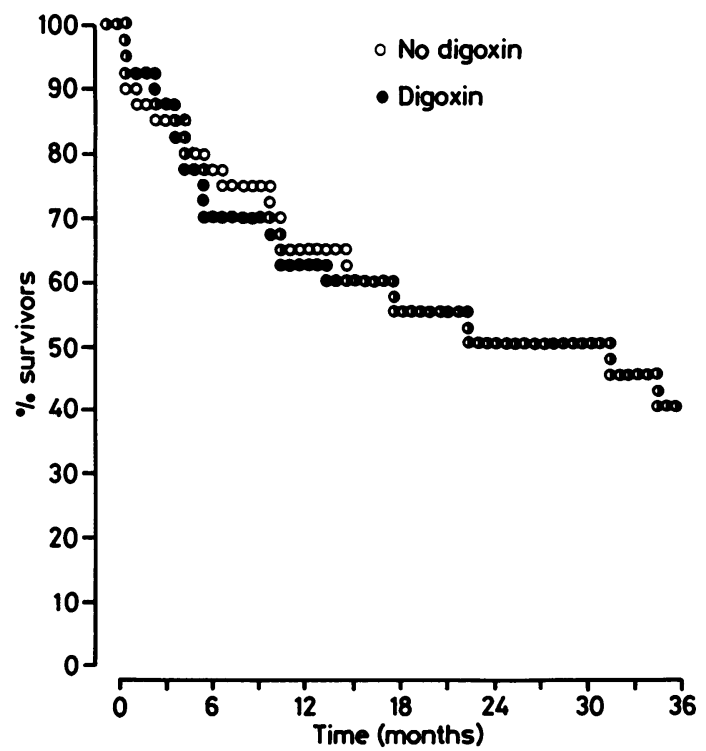

Fig 3 Log rank survival curves comparing patients treated with or without digoxin. No difference was noted.

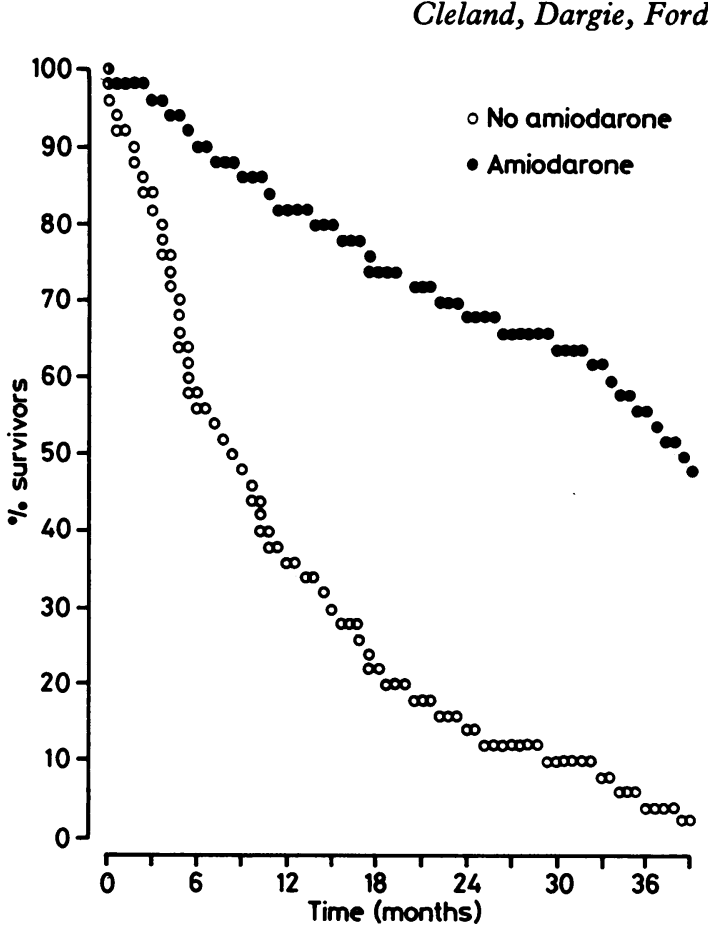

Fig 4 Estimated survival function of patients with or without amiodarone treatment. The frequency of ventricular extrasystoles, the mean arterial pressure, serum potassium, and exercise time were all fixed at median values and all patients were designated as having coronary artery disease (the largest diagnostic subgroup).

\section{COMPARISON OF RISK FACTORS IN}

DIAGNOSTIC SUBGROUPS

Those subjects with heart failure caused by coronary artery disease had a significantly lower blood pressure than those without coronary artery disease $(89$ (12) vs 94 (16) $\mathrm{mm} \mathrm{Hg}$; $\mathrm{p}<0.01$ ) and a lower frequency of ventricular arrhythmias (3950 vs $4875 / 24$ hours; $p<0.02)$. The duration of symptoms before entry was also shorter $(12.9$ (14.7) vs $25.7(21.1)$ months; $p<0.01)$. In other respects, including ventricular function (fractional shortening $15.5(6.3) \%$ vs $15.0(6.8) \%$ ), exercise time $(7.5(4.6)$ vs $7.4(4.9)$ minutes), and serum potassium (3.9 (0.4) vs $3.8(0.4)$ $\mathrm{mmol} / \mathrm{l})$ they were similar to patients in other diagnostic groups.

\section{RELATION OF MEAN ARTERIAL PRESSURE TO} OTHER MEASURED VARIABLES

The set of variables with the best independent relation to mean arterial pressure was serum sodium $(\mathrm{r}=0.54 \mathrm{p}<0.001)$, New York Heart Association score $(r=-0.41 p<0.001)$, and end diastolic left ventricular dimension $(r=-0.29 p<0.01)$. 


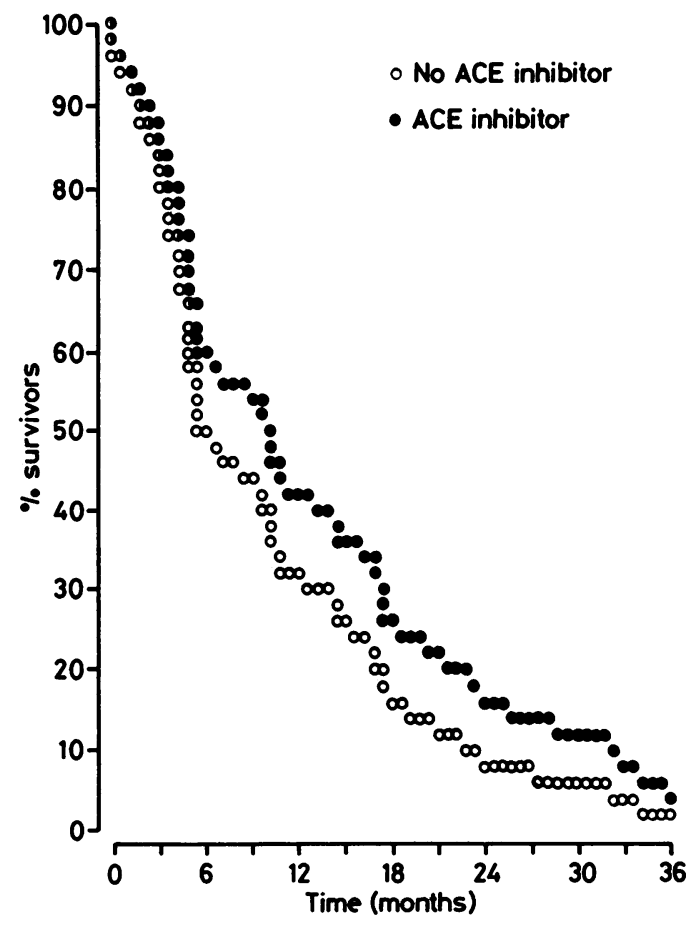

Fig 5 Estimated survival curve for patients with or without angiotensin converting enzyme inhibitors. Again all important prognostic factors were fixed at median values; patients were designated as having coronary artery disease but not receiving amiodarone.

\section{RELATION OF SERUM POTASSIUM AND} EXERCISE TIME TO OTHER MEASURED

\section{VARIABLES}

Only serum sodium $(r=0.40 p<0.001)$ was found to have a significant and independent relation to serum potassium. Exercise time was best related on stepwise regression to New York Heart Association score $(r=-0.79 ; p<0.0001)$ and fractional shortening $(r=0.31 ; p<0.001)$.

\section{ESTIMATED SURVIVAL CURVES}

The estimated survival curves for amiodarone versus no amiodarone treatment again suggested significant improvement in survival with amiodarone (fig 4). The estimated survival curves still suggested no pronounced beneficial effect with angiotensin converting enzyme inhibitors (fig 5 ), but also suggested no deleterious effect with digoxin use.

The estimated survival curves for prognostic indicators suggested that clinically meaningful separation could be made on the basis of the frequency of ventricular extrasystoles (fig 6), a diag- nosis of coronary artery disease (fig 7), mean arterial pressure (fig 8), exercise time (fig 9), and serum potassium (fig 10).

\section{Discussion}

Several recent studies in populations of patients with heart failure with varying diagnoses have reported conflicting results for the most reliable independent indicators of prognosis. ${ }^{1313}$ Some suggest that ventricular arrhythmias are the most powerful independent indicators ${ }^{157}$ but others have not confirmed this. ${ }^{11-13}$ It may be that ventricular arrhythmias merely reflect the extent of left ventricular dysfunction. ${ }^{5101323}$ These different views may be a reflection of different study populations, with arrhythmias in heart failure caused by idiopathic dilated cardiomyopathy showing a good relation with the extent of left ventricular dysfunction in some studies ${ }^{24}$ but not in others. ${ }^{13}$ In patients with ischaemic heart disease and left ventricular dysfunction, arrhythmias seem to be poorly related to the extent of dysfunction. ${ }^{710}$ Some studies suggest that indices of cardiac function and the severity of symptoms are helpful in predicting the prognosis of

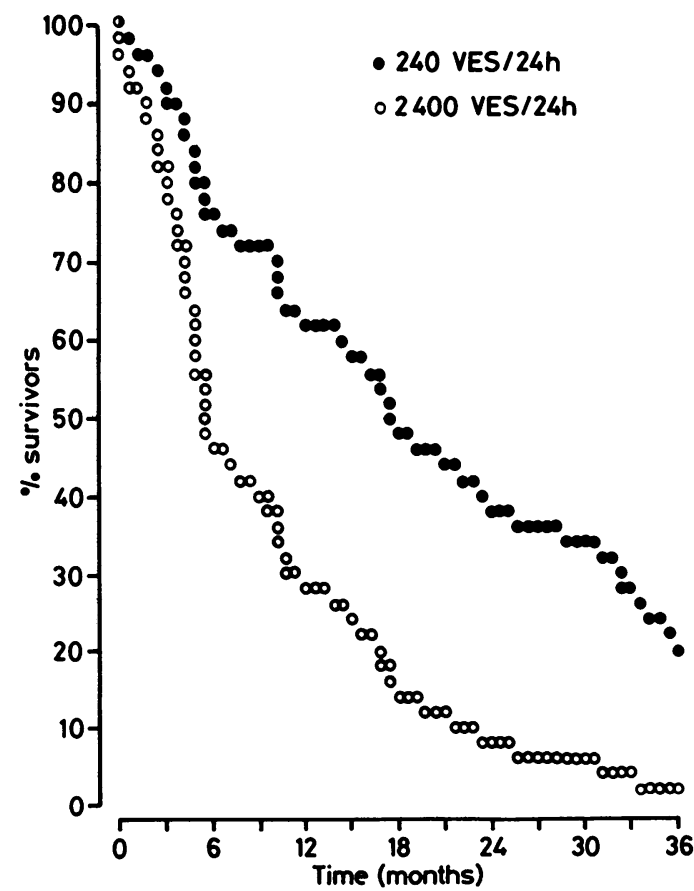

Fig 6 Estimated survival curve for patients with a high and a low frequency of ventricular extrasystoles (VES). Values were chosen arbitrarily. Patients had other important prognostic factors fixed at median values and were assumed to have coronary artery disease but not to be taking amiodarone. 


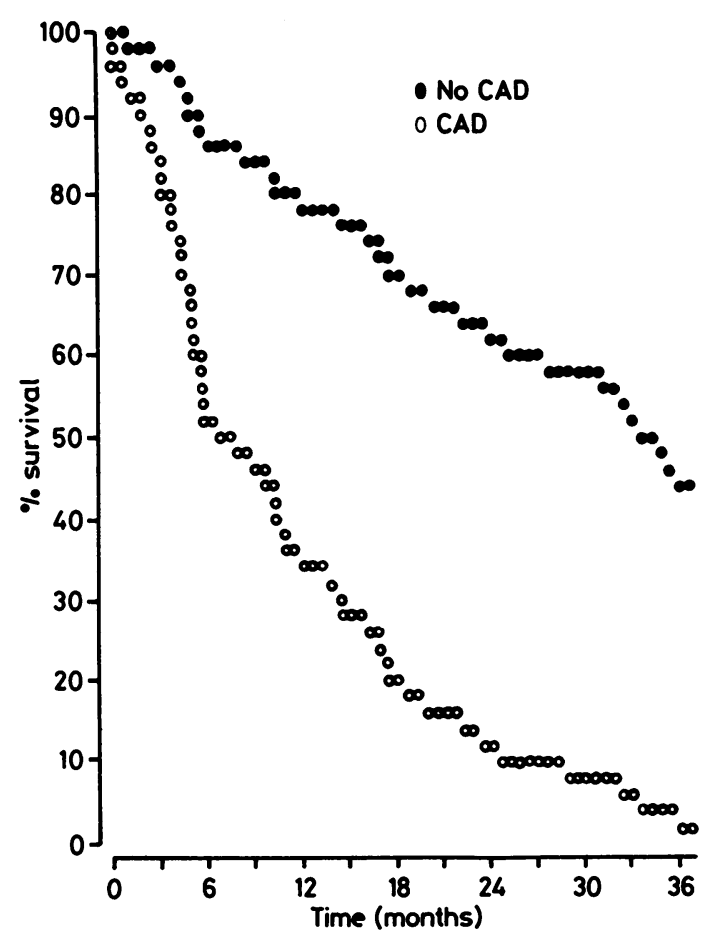

Fig 7 Estimated survival curve for patients with or without coronary artery disease. Patients had other important prognostic factors fixed at median values and were assumed not to be taking amiodarone.

patients with heart failure. ${ }^{21225}$ Left bundle branch block $^{526}$ serum sodium concentration, ${ }^{327}$ mean arterial pressure, ${ }^{2}$ exercise performance, ${ }^{28}$ and central venous plasma noradrenaline concentration ${ }^{3}$ have also been found to be useful in some studies. But for each of these indices there are conflicting studies. ${ }^{29-31}$

This study clearly demonstrates that the frequency of ventricular extrasystoles is strongly associated with a poor prognosis in patients with chronic heart failure caused by left ventricular dysfunction. That death is due to ventricular arrhythmias cannot be proved in a study like this one, but the high frequency of sudden death and low frequency of death caused by intractable heart failure suggest that the great majority of deaths in such patients are the result of arrhythmias. The lack of a significant relation between more complex ventricular arrhythmias and mortality may reflect the relatively short period over which we recorded the electrocardiogram. We have confirmed that complex ventricular arrhythmias relate closely to the frequency of simple extrasystoles, as has been previously noted. $^{1}$
The frequency of sudden death in this study is higher than the figure of around $50 \%$ reported in some studies. This may reflect differences in both the chosen patient population and differences in reporting. Other investigators have tended to exclude from the sudden death group patients with some deterioration in their condition before death, though the terminal event may none the less have been sudden, unexpected, and potentially arrhythmic. On the other hand we have adopted a very rigid definition of death caused by heart failure.

Our study suggests that arrhythmias are more closely related to functional class and exercise performance than to indices of resting left ventricular performance. The lack of a relation between prognosis and $M$ mode echocardiographic measurements of left ventricular function should be interpreted with caution especially when comparing different subjects with ventricles that have been damaged by ischaemia. However, several studies with invasive haemodynamics have also suggested a poor relation with prognosis. ${ }^{25}$ The relatively poor relation of exercise performance to left but not to right ventric-

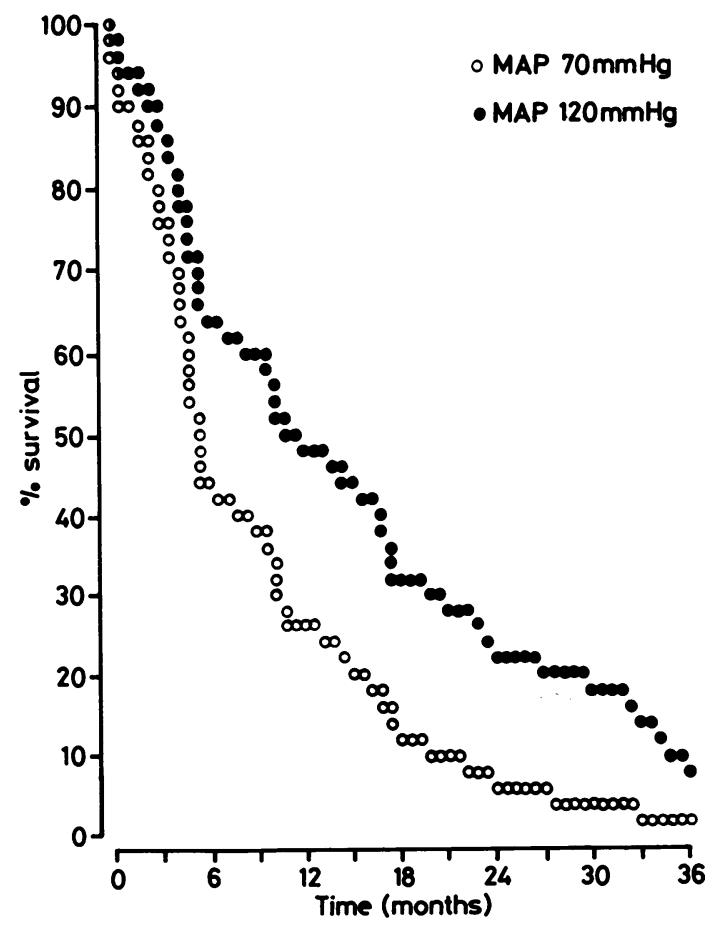

Fig 8 Estimated survival curve for patients with a high or a low mean arterial pressure (MAP). Values were chosen arbitrarily. Patients had other important prognostic factors fixed at median values and were assumed to have coronary artery disease but not to be taking amiodarone. 


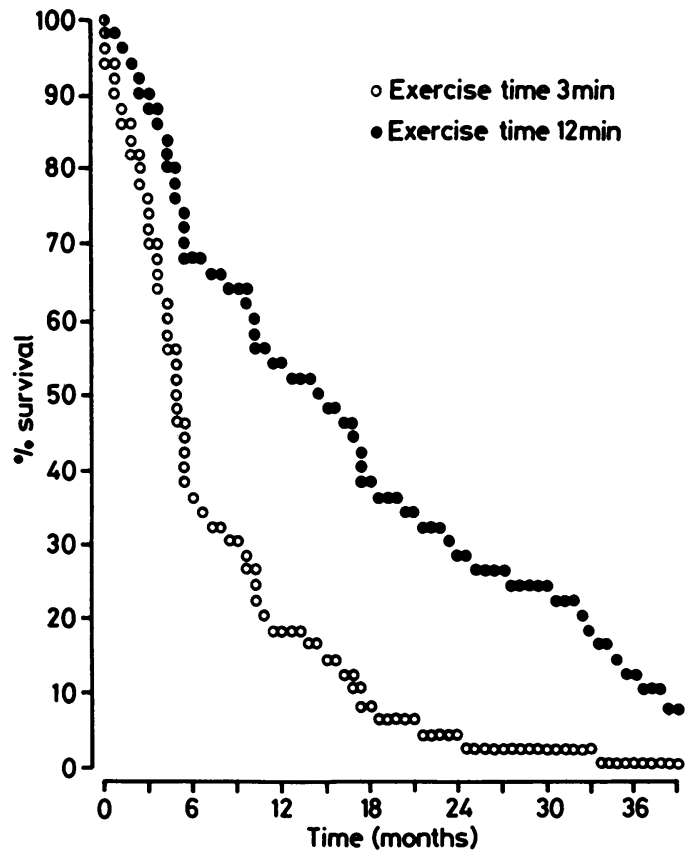

Fig 9 Estimated survival curve for patients with a short or a long exercise time in the modified Bruce protocol. Values were chosen arbitrarily. Patients had other important prognostic factors fixed at median values and were assumed to have coronary artery disease but not to be taking amiodarone.

ular haemodynamic function has been well documented. ${ }^{3233}$ The relation between exercise performance and prognosis may suggest this is a better index of cardiac performance. ${ }^{28}$

Hypokalaemia was more closely associated with ventricular arrhythmias than has been suggested previously, ${ }^{34}$ though a direct causal relation cannot be confirmed. The association may have been increased by use of digoxin, ${ }^{35-37}$ since hypokalaemia may enhance myocardial digoxin binding. ${ }^{36}$ Hypokalaemia may also be an index of depletion of total body reserves of potassium. ${ }^{38} 39$

We were unable to demonstrate any direct effect of therapeutic concentrations of digoxin on arrhythmias in heart failure, perhaps because of the wide interindividual susceptibility to arrhythmias or to the counterbalancing effect of an improvement in left ventricular function. ${ }^{40}$

It is likely that local myocardial ultrastructural and metabolic factors together with focal ischaemia caused by coronary vascular disease or excessive myocardial wall tension also lead to arrhythmias; these would not have been detected by our screening methods. Increased sympathetic activity might also give rise to arrhythmias ${ }^{41}$ and because sympathetic activity appears greatest in subjects with the lowest mean arterial pressure ${ }^{42}$ this is one mechanism by which low blood pressure may be related to arrhythmias.

A low mean blood pressure was also found to be of prognostic significance, as has been noted by others. ${ }^{2}$ Plasma renin and catecholamines are known to be inversely related to blood pressure in heart failure ${ }^{42}$ and a recent study has suggested that concentrations of plasma noradrenaline and to a lesser extent plasma renin are of prognostic significance in heart failure, ${ }^{3}$ though this has been disputed. ${ }^{7}$ Our study also demonstrates the inverse relation between blood pressure and serum sodium. Low blood pressure appears also to be a marker of clinically more severe heart failure because it is associated with worse New York Heart Association scores and poorer exercise performance.

The poorer prognosis in patients with coronary artery disease noted in this and other studies ${ }^{2}$ appears related to sudden death rather than reinfarction. Transient focal ischaemia may have caused arrhythmias even though angina was not a feature of this study group. The shorter duration of symp-

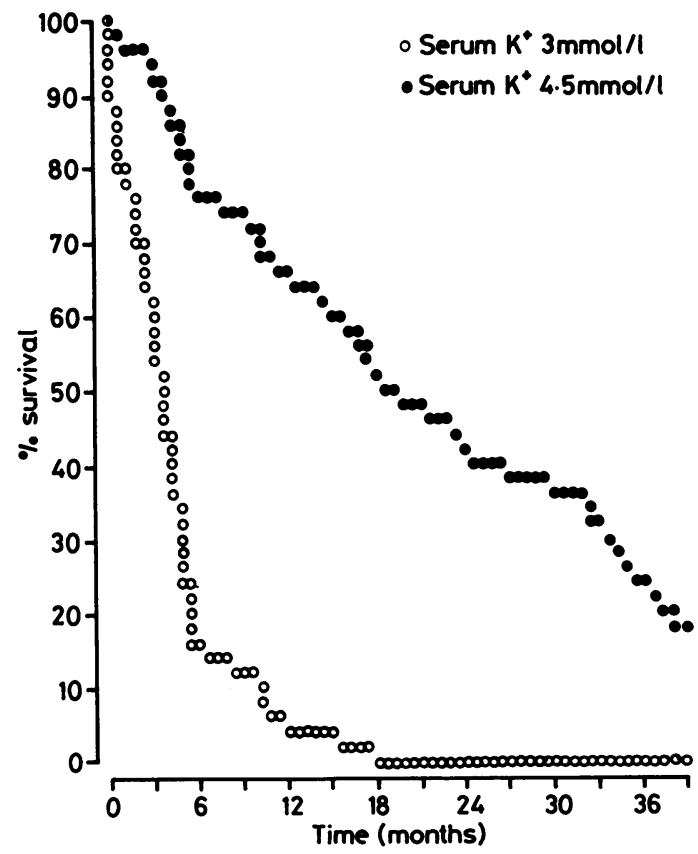

Fig 10 Estimated survival curve for patients with a high or a low initial mean serum concentration of potassium. Values were chosen arbitrarily. Patients had other important prognostic factors fixed at median values and were assumed to have coronary artery disease but not to be taking amiodarone. 
toms, lower mean blood pressure, and lower incidence of arrhythmias in those with coronary artery disease should also be noted.

The widely divergent estimated survival curves that we found not only for amiodarone treatment, but also for the frequency of ventricular arrhythmias, the diagnosis of coronary artery disease, arterial pressure, exercise time, and serum potassium suggest that the factors we have described are of clinical relevance. These clinical variables could be used to define an individual patient's likely prognosis.

The effect of vasodilators on prognosis remains controversial, ${ }^{174344}$ while angiotension converting enzyme inhibitors appear to have beneficial effects on prognosis. ${ }^{184345}$ Attempts have been made with antiarrhythmic drugs to improve the prognosis in heart failure. Some drugs such as disopyramide ${ }^{46}$ and flecainide ${ }^{47}$ seem to be unsuitable because of their negative inotropic action, while experience with other class I agents such as procainamide ${ }^{14}$ has not been fruitful. Agents such as $\beta$ blockers and verapamil ${ }^{48} 49$ are also negative inotropes; these also seem unsuitable for use in this area, though there is conflicting evidence of a beneficial effect of $\beta$ blockers in heart failure. ${ }^{5051}$

Depression of ventricular function by amiodarone at rest or during exercise is rare when modest doses are used. ${ }^{5253}$ Amiodarone also effectively suppresses ventricular arrhythmias in patients with heart failure, ${ }^{17}$ presumably accounting for the pronounced reduction in sudden death. The improvement in prognosis noted in the present study may not be entirely the result of its antiarrhythmic actions. Amiodarone also has antiischaemic effects which may be beneficial in idiopathic dilated cardiomyopathies as well as in heart failure related to coronary artery disease.

The relatively low maintenance dose of amiodarone used in this study limited the frequency of side effects. We have also noted worsening of arrhythmias in patients with heart failure when a loading dose of amiodarone of $200 \mathrm{mg}$ three times a day was given. Such patients have responded to a more gradual introduction of amiodarone $100-200 \mathrm{mg}$ once daily. Though the PR interval was prolonged in several patients on amiodarone we found only one case of higher grade block (2:1 block).

We were unable to demonstrate any effect on overall prognosis associated with the use of either digoxin or angiotensin converting enzyme inhibitors, nor did the dose of diuretic exert any powerful effect. The group treated with angiotensin converting enzyme inhibitors had worse heart failure, however, and the statistical analysis may not have compensated for this difference. A large controlled study has demonstrated a pronounced reduction in mortality rates in patients with very severe heart failure treated with enalapril. ${ }^{18}$ Interestingly, in patients with severe heart failure deaths from progressive heart failure were reduced but not sudden deaths. This contrasts with the rise in mortality associated with the use of some inotropic agents in heart failure. ${ }^{54}$ In our study, the incidence of sudden death was significantly reduced in those on angiotensin converting enzyme inhibitors; this may have been attributable to correction of hypokalaemia and hypomagnesaemia and intracellular potassium depletion, beneficial haemodynamic effects, and a reduction in sympathetic activity. ${ }^{556}$ The statistically insignificant increase in the frequency of vascular events suggests that angiotensin converting enzyme inhibitors should be used with caution in patients with known critical arterial stenoses. Potential deleterious effects of digoxin and higher doses of diuretics may have been masked by the use of amiodarone and captopril, but they did not seem to exert any powerful influence on prognosis.

We thank Dr John Reid, Dr John Kennedy, and Dr John McArthur for allowing us to study many of their patients. JGFC was supported by a Medical Research Council Training Fellowship and latterly by a Squibb Cardiovascular Fellowship during this study.

\section{References}

1 Meinertz T, Hofmann T, Kasper W, et al. Significance of ventricular arrhythmias in idiopathic dilated cardiomyopathy. Am J Cardiol 1984;53:902-7.

2 Franciosa JA, Wilen M, Ziesche S, Cohn JN. Survival in men with severe chronic left ventricular failure due to either coronary artery disease or idiopathic dilated cardiomyopathy. Am J Cardiol 1983;51: 831-6.

3 Cohn JN, Levine TB, Olivari MT, et al. Plasma norepinephrine as a guide to prognosis in patients with chronic congestive heart failure. $N$ Engl J Med 1984;311:819-23.

4 McKee PA, Castelli WP, McNamara PM, Kannel WB. The natural history of congestive heart failure: the Framingham study. $N$ Engl J Med 1971;285:1441-6.

5 Unverferth DV, Magorien RD, Moeschberger ML, Baker PB, Fetters JK, Leier CV. Factors influencing the one-year mortality of dilated cardiomyopathy. Am J Cardiol 1984;54:147-52.

6 Milner PG, Platia EV, Reid PR, Griffith LSC. Ambulatory electrocardiographic recordings at the time of fatal cardiac arrest. Am J Cardiol 1985;56:588-92.

7 Holmes J, Kubo SH, Cody RJ, Kligfield P. Arrhythmias in ischaemic and nonischaemic dilated cardiomyopathy; prediction of mortality by ambulatory electrocardiography. Am J Cardiol 1985;55:146-51. 
8 McKenna WJ, Krikler DM, Goodwin JF. Arrhythmias in dilated and hypertrophic cardiomyopathy. Med Clin North Am 1984;68:983-1000.

9 Shugoll GI, Bowen PJ, Moore JP, Lenkin ML. Follow up observations and prognosis in primary myocardial disease. Arch Intern Med 1972;129:67-72.

10 Bigger JT, Fleiss. JL, Kleiger R, Miller JP, Rolnitzky LM. The relationship among ventricular arrhythmias, left ventricular dysfunction, and mortality in the 2 years after myocardial infarction. Circulation 1984;68:250-8.

11 Shirey EK, Proudfit WL, Hawk WA. Primary myocardial disease. Correlation with clinical findings, angiographic and biopsy diagnosis. Follow up of 139 patients. Am Heart J 1980;99:198-207.

12 Wilson JR, Schwartz JS, Sutton MSJ, et al. Prognosis in severe heart failure: relation to haemodynamic measurements and ventricular ectopic activity. $J \mathrm{Am}$ Coll Cardiol 1983;2:403-10.

13 Von Olshausen K, Schäfer A, Mehmel HC, Schwarz F, Senges J, Kübler W. Ventricular arrhythmias in idiopathic dilated cardiomyopathy. Br Heart J 1984; 51:195-201.

14 Chakko CS, Gheorghiade M. Ventricular arrhythmias in severe heart failure: incidence, significance, and effectiveness of antiarrhythmic therapy. Am Heart J 1985;109:497-504.

15 Mestroni L, Fonda F, Camerini F. Ventricular arrhythmias in congestive cardiomyopathy. $N$ Engl $J$ Med 1983;309:377-8.

16 Poll DS, Marchlinski FE, Buxton AE, Doherty JU, Waxman HL, Josephson ME. Sustained ventricular tachycardia in patients with idiopathic dilated cardiomyopathy: electrophysiologic testing and lack of response to antiarrhythmic drug therapy. Circulation 1984;70:451-6.

17 Cohn JN, Archibald DGA, Ziesche S, et al. Effect of vasodilator therapy on mortality in chronic congestive heart failure. $N$ Engl $J$ Med 1986;314: 1547-52.

18 The CONSENSUS Trial Study Group. Effects of enalapril on mortality in severe congestive heart failure. $N$ Engl J Med 1987;316:1429-35.

19 Cleland JGF, Dargie HJ, Findlay IN, Wilson JT. Clinical, haemodynamic, and antiarrhythmic effects of long term treatment with amiodarone of patients in heart failure. Br Heart $J$ 1987;57:436-45.

20 Peto R, Peto J. Asymptotically efficient rank invariant procedures. J Roy Statist Soc 1972;135(series A): 185-207.

21 Cox DR. Regression models and life tables. $J$ Roy Statist Soc 1972;136(series B):187-220.

22 BMDP. BMDP statistical software. Los Angeles: University of California Press, 1983.

23 Glover DR, Littler WA. Factors influencing survival and mode of death in severe chronic ischaemic heart disease. Br Heart $J$ 1987;57:125-32.

24 Diaz R, Obasohan A, Newman H, Goodwin JF, Oakley C. Prognostic indicators in dilated cardiomyopathy [Abstract]. Br Heart $J$ 1985;53:114.

25 Fuster V, Gersh B, Giullani G, Tajik A, Brandenburg $R$, Frye $R$. The natural history of idiopathic dilated cardiomyopathy. Am J Cardiol 1981;47:525-31.

26 Convert G, Delaye J, Beaune J, Biron A, Gonin A. Prognosis of primary non-obstructive cardiomyopathies. Arch Mal Coeur 1980;73:227-37.

27 Lee WH, Packer M. Prognostic value of serum sodium concentration in severe heart failure and its modification by converting enzyme inhibition [Abstract]. Circulation 1984;70(suppl II):II-113.

28 Szlachic J, Massie BM, Kramer BL, Topic N, Tubau $\mathrm{J}$. Correlates and prognostic implication of exercise capacity in chronic congestive heart failure. $A m J$ Cardiol 1985;55:1037-42.

29 Graboys TB, Lown B, Podrid PJ, DeSilva R. Longterm survival of patients with malignant ventricular arrhythmia treated with antiarrhythmic drugs. $A m \mathrm{~J}$ Cardiol 1982;50:437-43.

30 Follansbee WP, Michelson EL, Morganroth J. Nonsustained ventricular tachycardia in ambulatory patients: characteristics and associations with sudden cardiac death. Ann Intern Med 1980;92:741-7.

31 Huang SK, Messer JV, Denes P. Significance of ventricular tachycardia in idiopathic dilated cardiomyopathy: observations in 35 patients. Am J Cardiol 1983;51:507-11.

32 Franciosa JA, Park M, Levine B. Lack of correlation between exercise capacity and indices of left ventricular performance in heart failure. Am J Cardiol $1981 ; 47: 33-9$.

33 Baker BT, Dinh H, Wilen MM, Boyd CM, Franciosa TA. Right but not left ventricular function relates to exercise capacity in chronic left ventricular failure [Abstract]. Circulation 1983;68(suppl III):III-9.

34 Medical Research Council Working Party on Mild to Moderate Hypertension. Ventricular extrasystoles during thiazide treatment: a sub-study of the MRC Mild Hypertension Trial. Br Med J 1983;287: 1249-53.

35 Shapiro W. Corrective studies of serum digitalis levels and the arrhythmias of digitalis intoxication. $\mathrm{Am} J$ Cardiol 1978;41:852-9.

36 Harrison CE, Brown AL. Myocardial digoxin-3H content in experimental hypokalaemic cardiomyopathy. J Lab Clin Med 1968;72:117-28.

37 Steiness E, Olesen KH. Cardiac arrhythmias induced by hypokalaemia and potassium loss during maintenance digoxin therapy. Br Heart $J$ 1976;38:167-72.

38 Cleland JGF, Dargie HJ, East BW, et al. Total body electrolyte composition in heart failure: the effects of captopril. Eur Heart J 1985;6:681-8.

39 Cleland JGF, Dargie HJ, Robertson I, Robertson JIS, East BW. Total body electrolyte composition in patients with heart failure: a comparison with normal subjects and patients with untreated hypertension. Br Heart J 1987;58:230-8.

40 Gradman AH, Cunningham M, Harbison MA, Berger HJ, Zaret BL. Effects of oral digoxin on ventricular ectopy and its relation to left ventricular function. Am J Cardiol 1983;51:765-9.

41 Reddy CP, Gettes LS. Use of isoproterenol as an aid to electrical induction of chronic recurrent ventricular tachycardia. Am J Cardiol 1979;44:705-13.

42 Dargie HJ, Cleland JGF, Leckie BJ, Inglis CG, 
East BW, Ford I. Relation of arrhythmias and electrolyte abnormalities to survival in patients with severe chronic heart failure. Circulation 1987;75: IV-98-102.

43 Furberg CD, Yusuf S. Effect of vasodilators on survival in chronic congestive heart failure. Am J Cardiol 1985;55:1110-2.

44 Walsh WF, Greenberg BH. Results of long-term vasodilator therapy in patients with refractory congestive heart failure. Circulation 1981;64:499-505.

45 Creager MA, Faxon DP, Halperin JL, et al. Determinants of clinical response and survival in patients with congestive heart failure treated with captopril. Am Heart J 1982;104:1147-54.

46 Sutton R. Haemodynamics of intravenous disopyramide. J Int Med Res 1976;4(suppl 1):46-8.

47 Josephson MA, Kaul S, Hopkins J, et al. Hemodynamic effects of intravenous flecainide relative to the level of left ventricular function in patients with coronary artery disease. Am Heart $J$ 1985;109:41-5.

48 Waagstein F, Hjalmarson $\AA$, Varnauskas E, Wallentin I. Effect of chronic beta-adrenergic receptor blockade in congestive cardiomyopathy. $\mathrm{Br}$ Heart $\mathrm{J}$ 1975;37:1022-36.

49 Taylor SH, Silke B. Haemodynamic effects of betablockade in ischaemic heart failure. Lancet 1981 ;ii: 835-7.
50 Ferlinz J, Easthope JL, Aronow WS. Effects of verapamil on myocardial performance in coronary artery disease. Circulation 1979;59:313-9.

51 Robinson C, Jackson G, Fisk C, Jewitt D. Haemodynamic effects of atenolol in patients with coronary artery disease. $\mathrm{Br}$ Heart $J$ 1978;40:22-8.

52 Trobaugh GB, Kudenchuk PJ, Green HL, et al. Effect of amiodarone on ventricular function as measured by gated radionuclide angiography. $\mathrm{Am} \mathrm{J}$ Cardiol 1984;54:1263-6.

53 Ellenbogen KA, O'Callaghan WG, Colavita PG, Smith MS, German LD. Cardiac function in patients on chronic amiodarone therapy. Am Heart J 1985; 110:376-81.

54 Packer M, Medina N, Yushak M. Hemodynamic and clinical limitations of long-term inotropic therapy with amrinone in patients with severe chronic heart failure. Circulation 1984;70:1038-47.

55 Cleland JGF, Dargie HJ, Ball SG, et al. Effects of enalapril in heart failure: a double blind study of effects on exercise performance, renal function, hormones, and metabolic state. Br Heart $J$ 1985;54:305-12.

56 Packer M, Medina N, Yushak M, Meller J. Hemodynamic patterns of response during longterm captopril therapy for severe chronic heart failure. Circulation 1983;68:803-12. 